\title{
Pharmacological induction of pancreatic islet cell transdifferentiation: relevance to type I diabetes
}

\author{
R Piran ${ }^{1}$, S-H Lee ${ }^{1}$, C-R Li ${ }^{2}$, A Charbono ${ }^{3}$, LM Bradley ${ }^{2}$ and F Levine ${ }^{\star, 1}$
}

Type I diabetes (T1D) is an autoimmune disease in which an immune response to pancreatic $\beta$-cells results in their loss over time. Although the conventional view is that this loss is due to autoimmune destruction, we present evidence of an additional phenomenon in which autoimmunity promotes islet endocrine cell transdifferentiation. The end result is a large excess of $\delta$-cells, resulting from $\alpha$ - to $\beta$ - to $\delta$-cell transdifferentiation. Intermediates in the process of transdifferentiation were present in murine and human T1D. Here, we report that the peptide caerulein was sufficient in the context of severe $\beta$-cell deficiency to induce efficient induction of $\alpha$ - to $\beta$ - to $\delta$-cell transdifferentiation in a manner very similar to what occurred in T1D. This was demonstrated by genetic lineage tracing and time course analysis. Islet transdifferentiation proceeded in an islet autonomous manner, indicating the existence of a sensing mechanism that controls the transdifferentiation process within each islet. The finding of evidence for islet cell transdifferentiation in rodent and human T1D and its induction by a single peptide in a model of T1D has important implications for the development of $\beta$-cell regeneration therapies for diabetes.

Cell Death and Disease (2014) 5, e1357; doi:10.1038/cddis.2014.311; published online 31 July 2014

The response of a tissue to stress/injury can involve cell death and proliferation. However, it has become increasingly recognized that changes in cellular differentiation state can have an important role. ${ }^{1}$ In type I diabetes (T1D), the established view has been that the primary pathophysiological event is $\beta$-cell apoptosis due to a $\beta$-cell specific autoimmune response, ${ }^{2}$ leading to profound $\beta$-cell deficiency. Thus, there has been great interest in inducing $\beta$-cell neogenesis, but there has been controversy over how and even whether $\beta$-cell regeneration occurs. ${ }^{3}$

Activation of dedicated stem/progenitor cells within the pancreas and transdifferentiation of other differentiated cell types to $\beta$-cells are two potential mechanisms. In the past, the prevailing paradigm has been that neogenesis proceeds by the activation of facultative $\beta$-cell stem/progenitors within pancreatic ducts. ${ }^{4-7}$ However, more recent studies have not found evidence of robust $\beta$-cell neogenesis from ducts. ${ }^{8-11}$ $\beta$-cell neogenesis from other cell types within the pancreas, including acinar $^{12}$ and centroacinar ${ }^{13}$ cells has also been reported.

Recently, we demonstrated robust $\beta$-cell neogenesis by transdifferentiation from preexisting $\alpha$-cells in a model of T1D where severe $\beta$-cell deficiency was induced by high-dose alloxan. ${ }^{14,15}$ In this model, $\beta$-cell neogenesis from $\alpha$-cells was stimulated by pancreatic duct ligation (PDL). ${ }^{9,15}$ Surgical reversal of PDL led to the recovery of $\beta$-cell mass and function by a combination of $\beta$-cell replication and $\beta$-cell neogenesis, demonstrating that $\beta$-cell regeneration by $\alpha$ - to $\beta$-cell neogenesis could be a robust approach to diabetes therapy, ${ }^{16}$ but PDL, which involves major surgery, is not a practical approach to therapy. Importantly, the relevance of $\alpha$ - to $\beta$-cell transdifferentiation to human biology remained unclear, as previous studies were performed in rodents.

Here, we report the occurrence of efficient islet cell transdifferentiation using an entirely pharmacologically based approach where the peptide caerulein, ${ }^{17,18}$ substituting for $\mathrm{PDL}$, stimulated $\beta$-cell transdifferentiation from $\alpha$-cells in mice rendered severely $\beta$-cell deficient by alloxan. Following caerulein plus alloxan, many of the neogenic $\beta$-cells went on to form $\delta$-cells. In murine and human T1D, a similar process appeared to occur, where $\alpha$-cells transdifferentiated into $\beta$-cells, which went on to form $\delta$-cells. This led to a marked $\delta$-cell excess in both murine and human T1D.

The finding of endocrine cell transdifferentiation in T1D supports a new paradigm where $\beta$-cells, in addition to undergoing destruction by inflammatory mediators, undergo a dynamic process of neogenesis from $\alpha$-cells and transdifferentiation to $\delta$-cells. Controlling the neogenic process could lead to a new approach to diabetes therapy.

\section{Results}

Caerulein plus alloxan induced $\alpha$-cells transdifferentiation into $\beta$-cells. As expected, ${ }^{17,19}$ caerulein-induced severe disruption of the acinar pancreas (Supplementary Figures $1 \mathrm{~A}-\mathrm{D}$ ) associated with almost the complete loss of the acinar cell marker amylase (compare Supplementary Figures $1 \mathrm{E}$ and $\mathrm{G})$. This was transient, with recovery by 11

\footnotetext{
${ }^{1}$ Sanford Children's Health Research Center, Sanford-Burnham Medical Research Institute, La Jolla, CA 92037, USA; ${ }^{2}$ Infectious and Inflammatory Disease Center, Sanford-Burnham Medical Research Institute, La Jolla, CA 92037, USA and ${ }^{3}$ Animal Facility, Sanford-Burnham Medical Research Institute, La Jolla, CA 92037, USA ${ }^{*}$ Corresponding author: F Levine, Sanford Children's Health Research Center, Sanford-Burnham Medical Research Institute, $10901 \mathrm{~N}$ Torrey Pines Road, La Jolla, CA 92037, USA. Tel: +1 858795 5179; Fax: +1 858795 5412; E-mail: flevine@sbmri.org

Abbreviations: T1D, type I diabetes; PDL, pancreatic duct ligation; eGFP, enhanced green fluorescent protein; $\mathrm{mG}$, membrane-localized enhanced green fluorescent protein; mT, membrane-localized Tomato; Glu, glucagon; PDX1, pancreas-duodenum homeobox 1; Nkx6.1, NK homeobox 6.1; nPOD, Network for Pancreatic Organ Donors with Diabetes

Received 30.3.14; revised 19.5.14; accepted 16.6.14; Edited by H-U Simon
} 
days post caerulein injection (Supplementary Figures 1A-D). Caerulin injection induced marked infiltration with CD3positive lymphocytes, in contrast with alloxan injection that did not induce lymphocytic infiltration (Supplementary Figures $1 \mathrm{E}-\mathrm{H}$ ). Caerulein had no effect on islet morphology or hormone expression (Supplementary Figures 1A-E). Alloxan induced $\beta$-cell ablation, which we found previously to be required for endocrine cell transdifferentiation ${ }^{9}$ (Supplementary Figures $1 \mathrm{G}$ and $\mathrm{H}$ ).

In our previous study of $\alpha$ - to $\beta$-cell transdifferentiation, employing PDL plus alloxan to induce transdifferentiation, ${ }^{9}$ the evidence for transdifferentiation as a cause of the increased $\beta$-cell mass was the finding of a high frequency of intermediates with glucagon-insulin coexpression, as well as the presence of little $\beta$-cell replication or neogenesis within ducts. $^{9}$ The high mortality following PDL plus alloxan hampered the genetic lineage tracing, which is considered to be the gold standard for determining lineage relationships. However, the alloxan plus caerulein model had lower mortality, allowing us to perform such studies.

For genetic lineage tracing of $\alpha$-cells, we used mice expressing membrane-localized enhanced green fluorescent protein (eGFP; membrane-localized enhanced green fluorescent protein $(\mathrm{mG})$ ) on their $\alpha$-cells while expressing membrane-localized Tomato (mT) on all other cells (Glu$\mathrm{mT} / \mathrm{mG}$; Figure 1a). Pancreases from Glu-mT/mG mice treated with alloxan alone or alloxan plus caerulein were analyzed 20 and 38 days post alloxan injection. In mice treated with alloxan alone, the few remaining $\beta$-cells expressed $\mathrm{mT}$. Following alloxan plus caerulein, insulinpositive cells expressing $\mathrm{mG}$, indicating an origin from recombined $\alpha$-cells, were easily detected (Figures $1 b-e, h$, quantified in i, Supplementary Movie 1). At day $20,5.5 \%$ of mG-positive cells were positive for insulin, which translated to $18 \%$ of all $\beta$-cells. All such cells were in islets. No mG-positive cells expressing glucagon or insulin were ever found in the ducts (Supplementary Figure 2). Following alloxan alone, mGpositive cells expressing insulin were extremely rare $(1 \%$ at day 20). At day 38 post caerulein plus alloxan, $9 \%$ of $\beta$-cells were mG-positive, compared with $1 \%$ following alloxan alone (Figure 1i). Considering that the $\alpha$-cell recombination efficiency in this experiment was $62 \%$ (Figure 1), approximately $29 \%$ of $\beta$-cells present at 20 days following alloxan plus caerulein arose from $\alpha$-cells. Thus, caerulein stimulated a dramatic increase in $\alpha$ - to $\beta$-cell transdifferentiation.

\section{Caerulein-induced transdifferentiation of $\alpha$-cells into} $\delta$-cells through a $\beta$-cell intermediate. A comparison between days 20 and 38 of the frequency of insulin-positive and somatostatin-positive cells revealed a substantial increase over time in mG-positive cells expressing somatostatin and a corresponding decrease in cells expressing insulin (Figures $1 \mathrm{f}$ and $\mathrm{g}$, quantified in i). Following alloxan plus caerulein, somatostatin-positive cells expressing $\mathrm{mG}$, indicating an origin from recombined $\alpha$-cells, rose from $2.1 \%$ of mG-positive cells at day 20 to $8.2 \%$ at day 38 (Figures 1b-e and h, quantified in i, Supplementary Movie 1), but were absent from samples from mice treated with alloxan alone. A cell coexpressing $\mathrm{mG}$, insulin and somatostatin is shown in Figure 1e, consistent with transdifferentiated $\beta$-cells going on to form $\delta$-cells. Following alloxan alone, no cells coexpressing $\mathrm{mG}$ and somatostatin were found (Figure 1i and Supplementary Movie 1).

Transdifferentiation of $\alpha$-cells induced by alloxan plus caerulein proceeded sequentially, with $\beta$-cells being formed initially, followed by $\beta$ - to $\delta$-cell transdifferentiation. Transdifferentiation of $\alpha$-cells to $\beta$ - and $\delta$-cells could have arisen by two possible routes; either as two independent transdifferentiation processes: $\alpha$ - to $\beta$-cells and $\alpha$ - to $\delta$-cells in parallel, or as a linear process where $\alpha$-cells convert to $\beta$ - and then to $\delta$-cells. To distinguish between those possibilities, we undertook a time course analysis to evaluate the frequency of intermediates in the process of transdifferentiation. This was done with $\mathrm{C} 57 \mathrm{BI} / 6$ mice, with a higher dose of caerulein (50 $\mu \mathrm{g} / \mathrm{kg} /$ injection), increasing the number of transdifferentiating cells from $12+/-2.3$ (Figure $1 \mathrm{j}$ ) to $22+/-4$ (Figure $2 \mathrm{j}$ ).

Mice were killed at days 13,20, 27 and 38 following alloxan plus caerulein or alloxan alone. At day 13 , islets in both groups consisted primarily of $\alpha$-cells and $\delta$-cells (Figures $2 \mathrm{~b}$ and $\mathrm{f}$, respectively-compare with normal islet in Figure 2a). However, at day 13 , there were consistently more $\beta$-cells in islets of the alloxan plus caerulein group $(7.8 \%$ of total endocrine cells) compared with the alloxan alone group (1.3\% of total endocrine cells; Figure $2 f$ versus b, quantified in j). This trend continued to day 20 , when $22 \%$ of the total endocrine cells in the alloxan plus caerulein group expressed insulin (Figure $2 \mathrm{~g}$ versus $\mathrm{c}$, quantified in $\mathrm{j}$ ), but the number of $\beta$-cells then declined at day 27 (Figure $2 \mathrm{~h}$ versus d, quantified in $\mathrm{j}$ ) and $3.7 \%$ at day 38 (Figure $2 \mathrm{i}$ versus e, quantified in j). Consistent with the lineage tracing study, the decreased number of $\beta$-cells occurred concomitantly with an increase in the number of $\delta$-cells (Figures $2 \mathrm{~g}-\mathrm{i}$, quantified in $2 \mathrm{k}$ ). The number of $\alpha$-cells did not change significantly (Figure 2l). This was expected, given our previous finding that $\alpha$-cells replicate following PDL plus alloxan. ${ }^{14}$

The initial rise in $\beta$-cell number followed by a decline (Figure $2 \mathrm{j}$ ), occurring concomitantly with a late rise in the number of $\delta$-cells (Figure 2k), was consistent with the genetic lineage tracing experiment (Figure 1i). Thus, both the lineage tracing and time course experiments support a model where

Figure 1 Genetic lineage tracing demonstrated transdifferentiation of $\alpha$-cells to $\beta$ - and $\delta$-cells following alloxan plus caerulein. (a) Glu-mT/mG mice were injected with caerulein and alloxan as described in the Materials and Methods section. The recombination efficiency in $\alpha$-cells was $0.62+I-0.047$ (S.E.M.), calculated as the number of $\alpha$-cells expressing eGFP/ $\alpha$-cells expressing eGFP(green) plus $\mathrm{mT}$ (red). (b and c) Representative low-power photomicrographs of islets from mice killed at days 20 and 38 , respectively, showing transdifferentiated $\beta$ - (blue) and $\delta$-cells (white). (d-h) High-power views of the regions from $\mathbf{b}$ and $\mathbf{c}$ showing lineage-marked cells expressing insulin ( $\mathbf{d}$ and $\mathbf{h}$ ), somatostatin (f and $\mathbf{g}$ ) or both (e). (i) Quantification of $\beta$ - and $\delta$-cell transdifferentiation from $\alpha$-cells. Note that no eGFP-positive cells expressing somatostatin were detected after alloxan alone. (j) Quantification of the frequency of islet cell types during alloxan alone or alloxan + caerulein at days 20 and 38 . For the day 20 time point, 317 cells islet cells were quantified in the alloxan alone condition and 605 cells were quantified in the alloxan plus caerulein condition. For the day 38 time point, 309 cells islet cells were quantified in the alloxan alone condition and 478 cells were quantified in the alloxan plus caerulein condition. Error bars are S.E.M. Scale bar for $\mathbf{c}-\mathbf{g}=10 \mu \mathrm{m}$ 
a
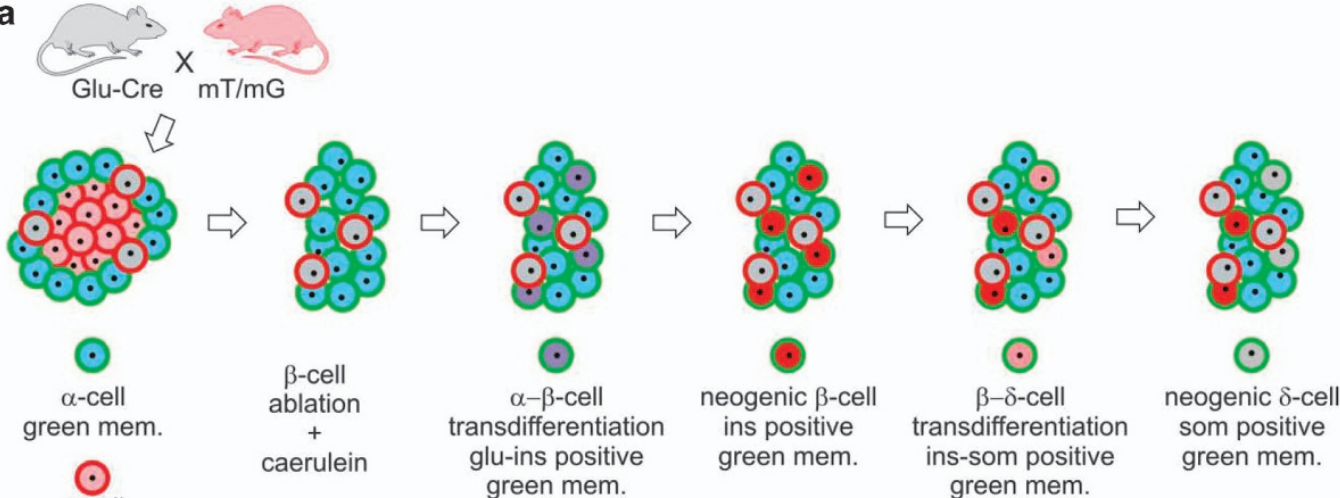

$\beta-c e$

red mem.

green mem.

green mem.

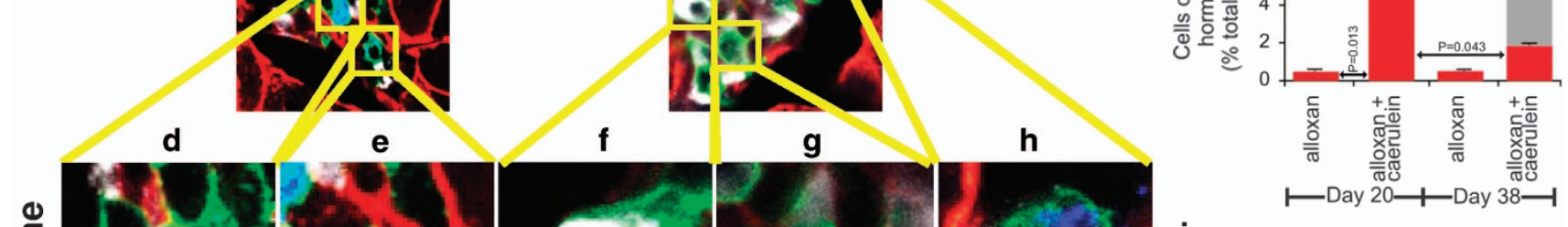

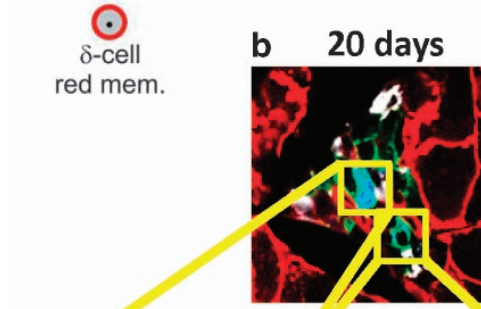

है

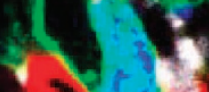

J

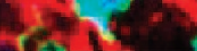

4

\section{c 38 days}
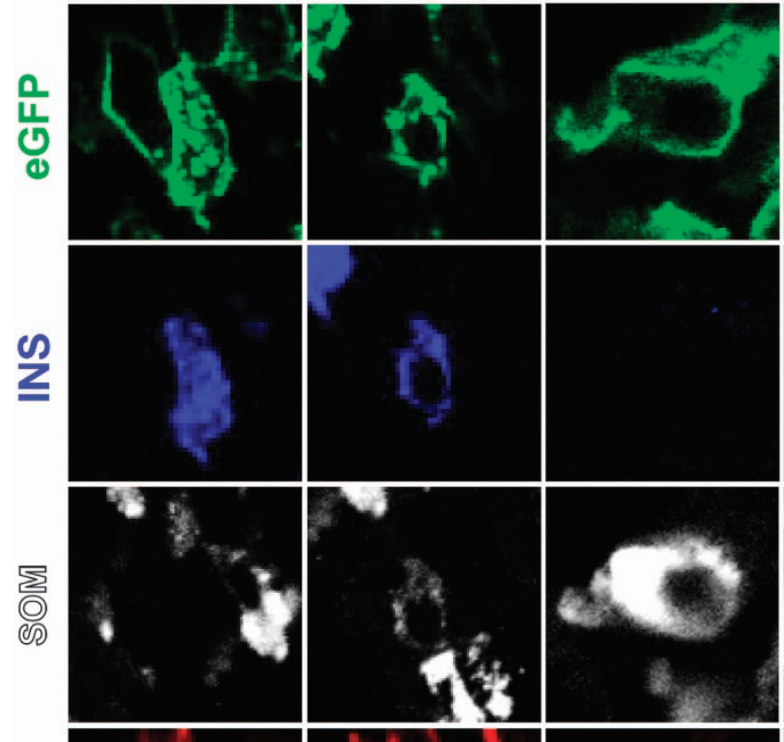

Ł
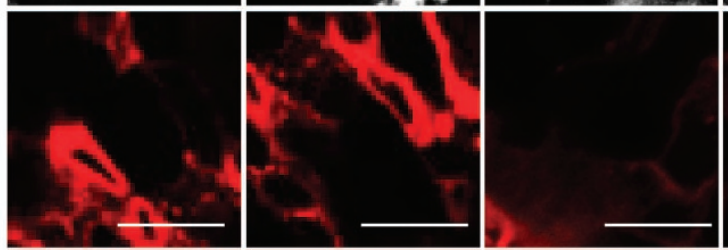
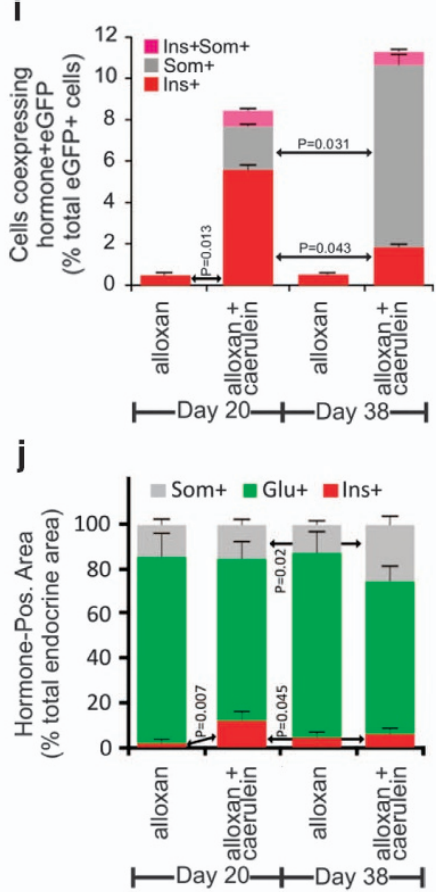
Day: 0

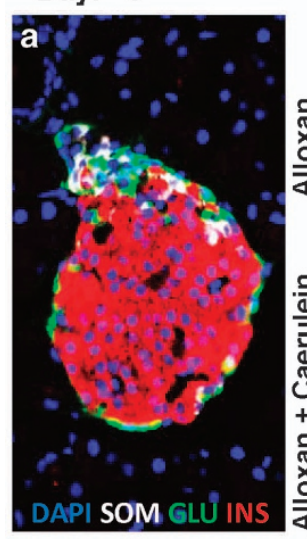

j

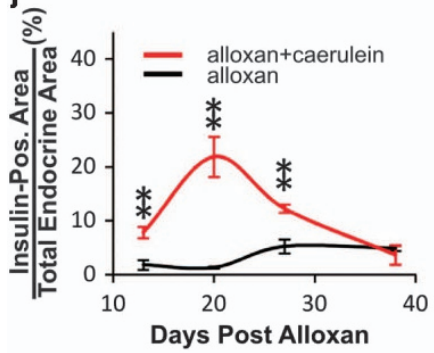

m

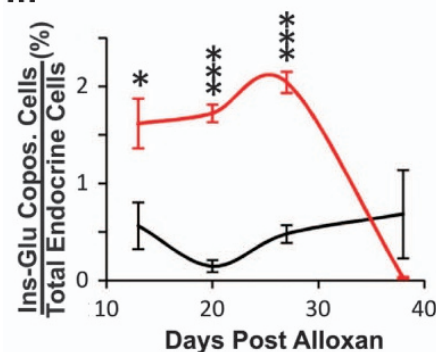

13

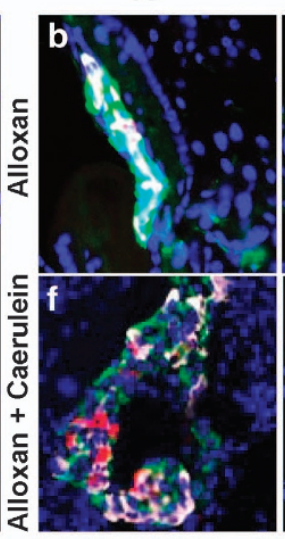

k

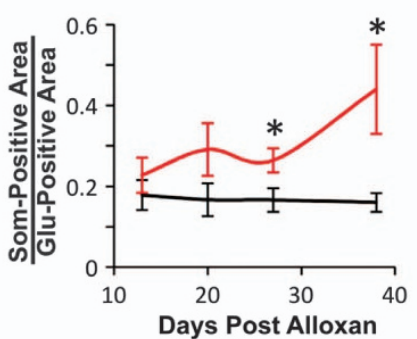

n

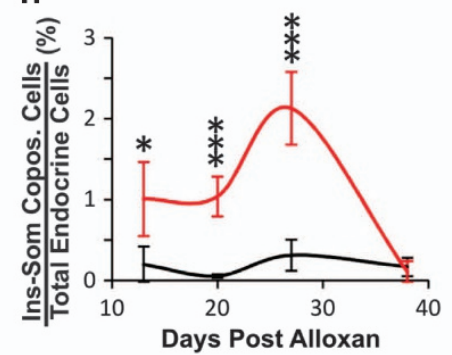

27
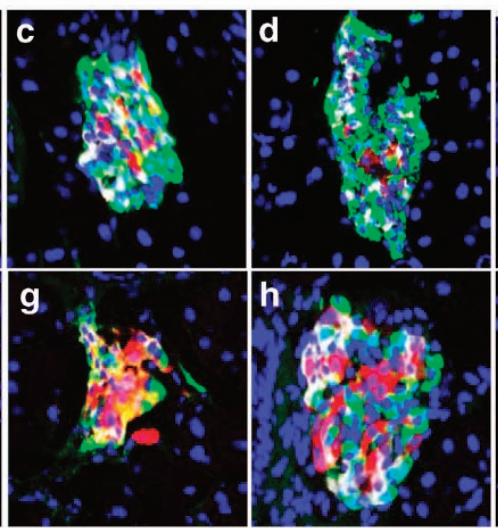

I
38
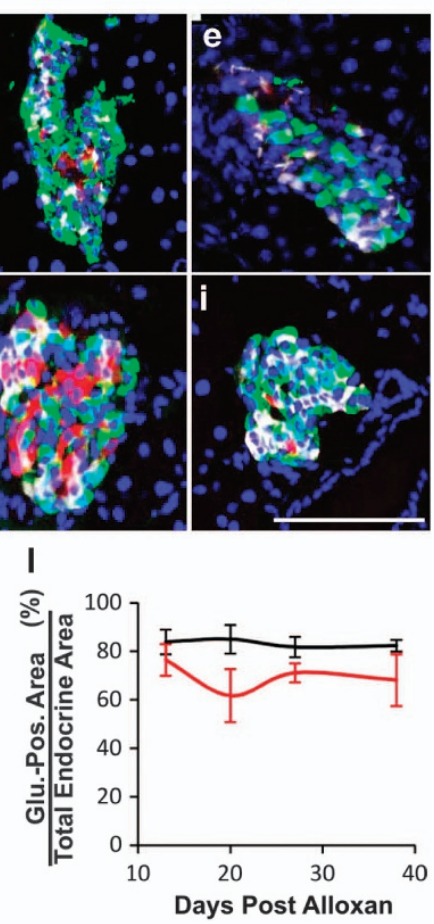

Figure 2 Time course analysis demonstrated the transdifferentiation from $\alpha$ - to $\beta$ - to $\delta$-cells following alloxan plus caerulein. Mice were killed and pancreas harvested at days 13,20,27 and 38 following the initiation of alloxan $+/$ - caerulein treatment on day 1. (a) A typical islet of Langerhans from an untreated C57BL/6 mouse demonstrating a preponderance of $\beta$-cells (insulin-red) located internal to a ring of $\alpha$-cells (glucagon-green) and $\delta$-cells (somatostatin-white). DAPI (blue nuclear stain). (b-e) Islets from mice injected with alloxan alone demonstrated continued preponderance of $\alpha$-cells, with few $\delta$-cells or residual $\beta$-cells over time. (f-i) Islets from mice injected with alloxan plus caerulein demonstrated a dramatic increase of $\beta$ - and $\delta$-cells over time. (j) Quantification of insulin-positive area over time, demonstrating a peak of $\beta$-cell formation at day 20 following alloxan plus caerulein (red line), with no significant change following alloxan alone (black line). (k) Quantification of the somatostatin-positive area normalized to the glucagon-positive area to control for effects of $\beta$-cell ablation on the somatostatin-positive area, demonstrating a continued increase of $\delta$-cell formation over time following alloxan plus caerulein, with no significant change following alloxan alone. (I) Quantification of glucagon-positive area over time, demonstrating a decrease in the number of $\alpha$-cells following alloxan plus caerulein (red line), with no significant change following alloxan alone. (m) Quantification of insulin-glucagon copositive area over time, demonstrating an increase of cells coexpressing insulin and glucagon following alloxan plus caerulein until day 38, when such cells were no longer present. There was no significant change in insulin-glucagon copositive cells following alloxan alone, never rising above the background. (n) Quantification of insulin-somatostatin copositive area over time, demonstrating an increase of cells coexpressing insulin and somatostatin following alloxan plus caerulein, peaking at day 27 and disappearing by day 38 . There was no significant change in insulin-somatostatin copositive cells following alloxan alone, never rising above the background. Error bars are $S . E . M .{ }^{*} P<0.05,{ }^{* \star} P<0.005$, ${ }^{* * *} P<0.0005$. Scale bar $=75 \mu \mathrm{m}$

transdifferentiation occurred by a process where $\alpha$-cells first converted into $\beta$-cells, with $\delta$-cell formation occurring later.

Intermediate cells predicted to exist as a consequence of $\alpha$ - to $\beta$ - to $\delta$-cell transdifferentiation are present following alloxan plus caerulein. A sequential process of $\alpha$ - to $\beta$ - to $\delta$-cell transdifferentiation should lead to intermediates with glucagon-insulin or insulin-somatostatin but not glucagon-somatostatin coexpression, whereas if $\delta$-cells formed directly from $\alpha$-cells, intermediate cell types coexpressing glucagon and somatostatin should be found. As predicted by the $\alpha$ - to $\beta$ - to $\delta$-cell model, glucagon-insulin coexpression was high at day 13 , the earliest time-point studied, declined at day 27 and persisted until day 38 (Figure 2m). Insulin-somatostatin coexpressing cells rose later, peaking at day 27 (Figure 2n). Glucagon-somatostatin coexpression was never found at any time-point.

The sequential model predicts that transcription factors expressed in $\beta$-cells should be found in cells with glucagon-insulin and insulin-somatostatin coexpression. 
Thus, we examined the expression of the transcription factors pancreas-duodenum homeobox 1 (PDX1) and NK homeobox 6.1 (NKX6.1). Both of the transcription factors are expressed in all $\beta$-cells, with NKX6.1 being highly $\beta$-cell specific, ${ }^{20,21}$ while PDX1 is also expressed in a low percentage of $\delta$-cells. ${ }^{22}$ Neither is detected in $\alpha$-cells. Following alloxan plus caerulein, there was a large increase in islet cells coexpressing PDX1 and glucagon, reaching a peak at day 13 when almost $25 \%$ of glucagon-positive cells also expressed PDX1 (Figure 3a, quantified in e). Such cells were not found in untreated (Figure 3a, Day 0) or alloxan-injected mice (Supplementary Figure 3A, quantified in Figure 3e).

Because of its specificity for $\beta$-cells in the adult, ${ }^{20,21} \mathrm{NKX6.1}$ was informative in revealing the sequence by which transdifferentiation occurred. Unlike PDX1, and in contrast to our previous study, ${ }^{9}$ no glucagon and NKX6.1 coexpression was found. With regard to $\delta$-cell neogenesis, if $\delta$-cells arose by a pathway involving a $\beta$-cell intermediate, there should be cells coexpressing somatostatin and NKX6.1, whereas if $\delta$-cells arose directly from $\alpha$-cells, NKX6.1 should never have been expressed and there should be no cells coexpressing somatostatin and NKX6.1. At day 20,10\% of the cells expressing somatostatin coexpressed NKX6.1 (Figure 3c, quantified in $\mathrm{g}$ ). These observations support a model where $\delta$-cell transdifferentiation from $\alpha$-cells obligatorily passes through a $\beta$-cell intermediate.

Cellular replication is a central aspect of stem cell biology. ${ }^{23}$ In an independent experiment, mice were administered BrdU continuously following alloxan plus caerulein to mark cells that had replicated. Both BrdU-positive and negative cells that coexpressed insulin and somatostatin coexpression were found at day 20 (Supplementary Figure 6). This is consistent with our previous study of islet cell transdifferentiation ${ }^{9}$ and indicates that transdifferentiation occurred independently of replication.

In the time course experiment, six mice were maintained for at least 38 days following alloxan plus caerulein, from which two exhibited reduced blood glucose over time, whereas the others remained diabetic (Supplementary Figure 7A). The mice with lower blood glucose were killed at days 38 and 62 . In contrast to mice treated with alloxan alone, where $\alpha$-cells were the predominant islet cell type at day 38 (Supplementary Figure 7B), and the alloxan plus caerulein mice that remained diabetic at day 38 and where $\delta$-cells predominated (Supplementary Figure 7C), the alloxan plus caerulein mice that became normoglycemic had many $\beta$-cells in their islets (Supplementary Figure 7D). The islets had an intermixing of $\alpha-, \beta$ - and $\delta$-cells (Supplementary Figures 7D-H).

Induction of islet cell transdifferentiation by alloxan plus caerulein was islet autonomous. Previously, we and others ${ }^{9,24}$ found that profound $\beta$-cell ablation was required to stimulate endocrine cell transdifferentiation. Moderate $\beta$-cell ablation (up to $80 \%$ ) led to $\beta$-cell replication rather than transdifferentiation. ${ }^{25}$ This suggested that $\alpha$-cells sensed the number of $\beta$-cells and only when that fell below a certain threshold did transdifferentiation occur. The sensing mechanism could be a local phenomenon where $\alpha$-cells sensed the proximate $\beta$-cell number, while sensing of the total $\beta$-cell mass was also a possibility.
Because the extent of $\beta$-cell ablation following alloxan injection varied between islets, we were able to measure the extent of transdifferentiation in islets that differed in the number of preexisting $\beta$-cells that survived alloxan. Using genetic lineage marking to distinguish between preexisting $\beta$-cells and neogenic $\beta$-cells, we counted the number of preexisting (mT expressing) and neogenic (mG expressing) $\beta$-cells in each islet. In islets with efficient $\beta$-cell ablation, there were many neogenic $\beta$-cells (Figures $4 a-c$ ), whereas in islets with many $\beta$-cells that survived alloxan, there was little to no transdifferentiation, that is, the $\beta$-cells expressed $\mathrm{mT}$ on their membranes (Figures $4 d-f)$. There was a threshold effect, with the vast majority of transdifferentiated $\beta$-cells being found in islets with 10 or fewer preexisting $\beta$-cells that survived alloxan treatment (Figure 4g, $P=0.0016$ ). Only two $\mathrm{mG}$-positive $\beta$-cells were found in islets with greater than ten preexisting $\beta$-cells. The threshold effect is consistent with a locally acting sensing mechanism where each islet behaves autonomously with respect to $\beta$-cell neogenesis from $\alpha$-cells.

Endocrine cell transdifferentiation in the NOD mouse model of T1D. A logical next step was to examine T1D, the prototypical disease that combines inflammation with $\beta$-cell deficiency, for evidence of islet cell transdifferentiation. As genetic lineage tracing is not available in NOD mice, hormone colocalization, which we and others have shown to indicate islet cell transdifferentiation, ${ }^{9,26,27}$ was used as a marker. As in the alloxan plus caerulein model, there was an increase in $\delta$-cells in the islets of NOD mice as they progressed from prediabetic to diabetic (Figure 5a, quantified in b and Supplementary Text).

Endocrine cell transdifferentiation in human T1D. To study transdifferentiation in human T1D (Supplementary Table 1), we first asked whether there was a $\delta$-cell excess. As expected, islets were composed primarily of $\alpha$-cells early in the course of disease (compare normal human pancreas in Figure $6 \mathrm{a}$ and Supplementary Figure 10 with early stage T1D pancreases in Figure $6 \mathrm{~b}$ and Supplementary Figure 11). As the number of years of diabetes increased, so did the frequency of $\delta$-cells (compare Figure $6 \mathrm{~b}$ and Supplementary Figure 11 with Figure $6 c$ and Supplementary Figure 12). The $\delta$ - to $\alpha$-cell ratio demonstrated a statistically significant increase as a direct function of the number of years of diabetes, which did not occur in non-diabetic or type II diabetic patients (Figures 6 e and f). In fact, the $\delta$ - $/ \alpha$-cell ratio decreased in type II diabetes with duration of diabetes (Figure 6d and Supplementary Figure 13, quantified in Figure $6 f$ ), most likely due to the $\alpha$-cell hyperplasia that occurs. ${ }^{28}$

For direct evidence of transdifferentiation, we examined for intermediates in the process, finding cells with glucagoninsulin or insulin-somatostatin coexpression in some patients (Figures $6 \mathrm{k}-\mathrm{x}$, quantified in $\mathrm{y}$ and $\mathrm{z}$, Supplementary Figures 11 and 14), but not in all (Figure 6c, Supplementary Figure 12). Cells coexpressing islet hormones were not found in non-diabetic controls (Figures $6 \mathrm{~g}-\mathrm{j}$, quantified in $\mathrm{y}$ and $\mathrm{z}$, Supplementary Figures 10 and 14) or patients with type II diabetes (Figure 6d, Supplementary Figure 13). No glucagonsomatostatin coexpressing cells were found in any patient. 
As in the mouse, we found islet cells coexpressing insulin, somatostatin and NKX6.1 in T1D but not normal pancreases (Supplementary Figure 15, compare the non-diabetic patient in A-D where NKX6.1 was restricted to $\beta$-cells, with the T1D patient in E-G where there were cells that coexpressed insulin, somatostatin and NKX6.1).

Although the fact that some patients with T1D exhibited glucagon-insulin coexpression indicated that $\alpha$-cells were
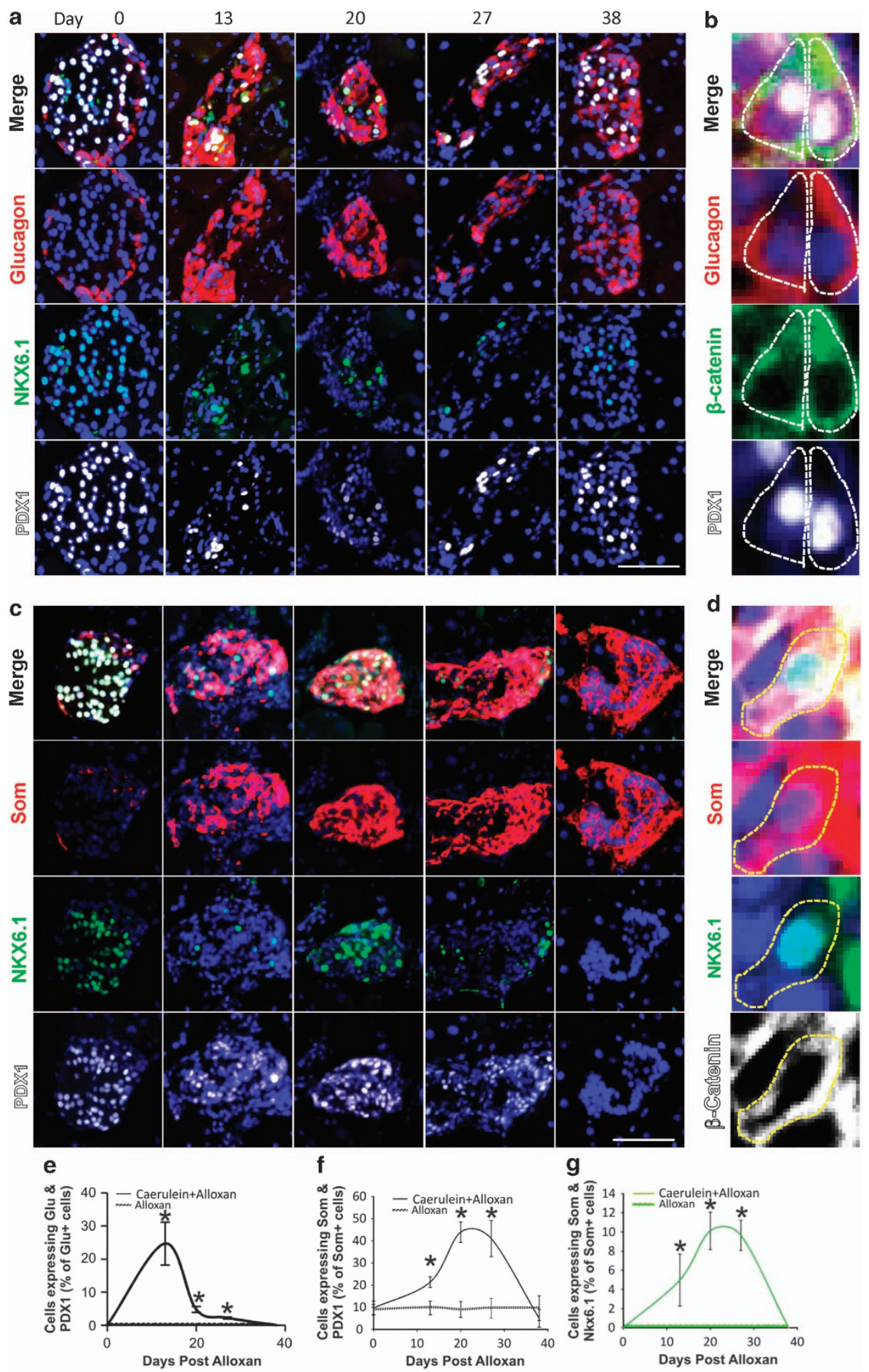
transdifferentiating into $\beta$-cells, the possibility of direct conversion of $\beta$-cells into $\delta$-cells remained. A 37-year-old female with T1D for 20 years (nPOD donor \#6038) who had a substantial number of residual $\beta$-cells was informative had a significant number of $\beta$-cells in most islets (Figures 6o-r, Supplementary Figures 11D, 14D and E), and

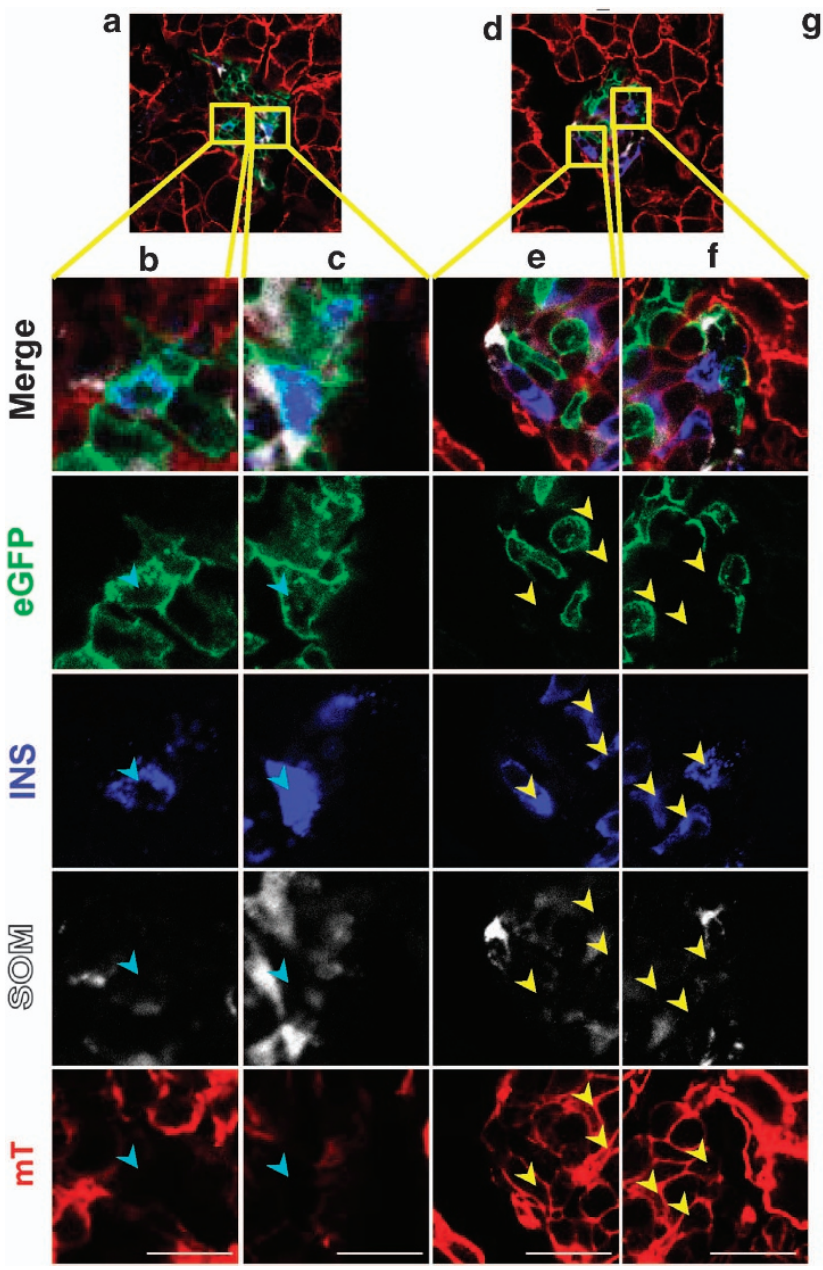

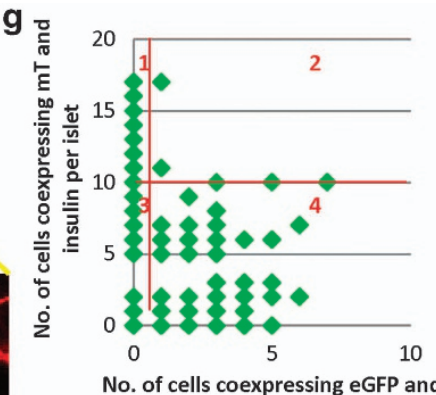

No. of cells coexpressing eGFP and insulin or somatostatin per islet

Figure 4 Endocrine cell transdifferentiation is islet autonomous. Photomicrographs of pancreas sections from lineage tracing mice killed 38 days following alloxan plus caerulein. (a) An islet with no preexisting $\beta$-cells (blue cytoplasmic insulin and red mT membrane fluorescence), demonstrating neogenic $\beta$-cells (blue cytoplasmic insulin and green eGFP membrane fluorescence; high-power views in $\mathbf{b}$ and $\mathbf{c}$, neogenic cells marked with cyan arrowheads). (d) An islet with many preexisting $\beta$-cells (high-power views in $\mathbf{e}$ and $\mathbf{f}$, preexisting cells marked with yellow arrowheads) demonstrating no neogenic $\beta$ - or $\delta$-cells. (g) Quantification of neogenic $\beta$ - and $\delta$-cells per islet. The number of preexisting $\beta$-cells in each islet (insulin,$+ \mathrm{mT}+$ ) was plotted against the number of neogenic $\beta$-plus $\delta$-cells (insulin or somatostatin + , eGFP + ) in that islet. The $P$-value for the difference between islets in which there were greater than 10 preexisting $\beta$-cells and at least one eGFP-positive cell expressing insulin or somatostatin (quadrant 2) versus islets in which there were ten or fewer $\beta$-cells expressing $\mathrm{mT}$ and at least one eGFP-positive cell expressing insulin or somatostatin (quadrant 4) was 0.0016 , calculated using a two sample proportion test with continuity correction in $R$. Scale bar for $\mathbf{b}-\mathbf{f}=10 \mu \mathrm{m}$

Figure 3 PDX1 and NKX6.1 expression in somatostatin- and glucagon-positive cells following alloxan plus caerulein. (a) Cells coexpressing PDX1 (white) and glucagon (red) were found transiently following alloxan plus caerulein, peaking at day 13 (quantified in e). Coexpression of glucagon and NKX6.1 (green) was not found. (b) $\beta$-catenin (green), which localizes primarily to the cell membrane, was used to outline cells to confirm coexpression of PDX1 (white) and glucagon (red) in the same cell. PDX1-glucagon coexpression frequently occurred in the absence of insulin expression (Supplementary Figure 4), suggesting that PDX1 induction was an early event in the process of $\alpha$ - to $\beta$-cell transdifferentiation. (c) Cells coexpressing NKX6.1 (green) and somatostatin (red) were found transiently following alloxan plus caerulein, peaking at day 20, but not after alloxan alone (quantified in $\mathbf{~}$; see also Supplementary Figure 3B). Note that in many of the cells coexpressing NKX6.1 and somatostatin at day 20, NKX6.1 was present in the cytoplasm (additional examples in Supplementary Figure 5). (d) $\beta$-catenin (white) was used to outline cells to confirm the coexpression of NKX6.1 (green) and somatostatin (red). No such cells were found in islets from mice injected with alloxan alone (Supplementary Figure 3B). Further examination of the cells coexpressing NKX6.1 and somatostatin revealed that in cells expressing somatostatin and NKX6.1 but not insulin, the NKX6.1 was invariably cytoplasmic (area outlined in red in Supplementary Figure $5 \mathrm{E}$ ) ${ }^{39}$ In cells that coexpressed NKX6.1, somatostatin and insulin, NKX6.1 was usually nuclear (Supplementary Figures 5C-F), but in rare cells was cytoplasmic. No cells coexpressing insulin and somatostatin but not NKX6.1 were found. Cytoplasmic expression of NKX6.1 has been described, with the suggestion that it is controlled by the redox state of the cell and that its localization may be important in Type II diabetes. ${ }^{39}$ PDX1 also exhibited a transient increase in expression in cells expressing somatostatin, peaking at day 20 (quantified in f), which did not occur following alloxan alone (Supplementary Figure 3 ) In alloxan-injected mice, expression of PDX1 in $\delta$-cells remained constant over time at $9.5 \%$ (Supplementary Figure 3B, quantified in Figure $3 \mathrm{f}$ ), but rose to more than $40 \%$ at day 20 in alloxan plus caerulein treated mice (Figure $3 \mathrm{c}$, quantified in f). Scale bar $=75 \mu \mathrm{m}$ 

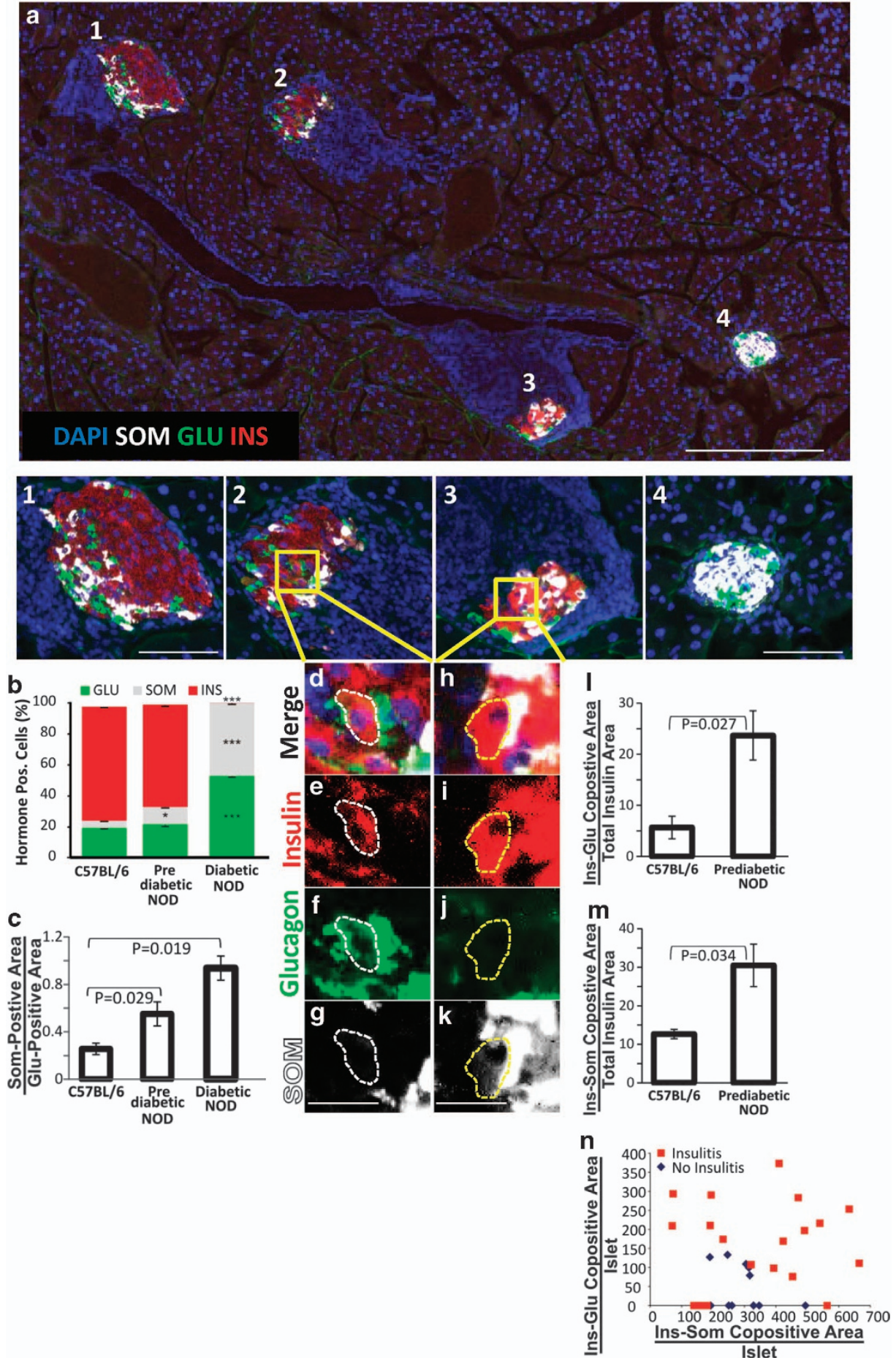

Figure 5 Endocrine cell transdifferentiation leads to an increase in $\delta$-cells during the progression to diabetes in NOD mice. (a) A low-power view (scale bar $=200 \mu \mathrm{m}$ ) of a prediabetic NOD mouse pancreas, with higher digital magnification (scale bars $=75 \mu \mathrm{m}$ ) of four islets that represent different stages in the progression of autoimmune diabetes with Islet 1 having an intact core of $\beta$-cells in the islet core, Islet 2 exhibiting islet disorganization, Islet 3 exhibiting islet disorganization, $\beta$-cell loss and $\delta$-cell increase and Islet 4 being composed almost entirely of $\delta$-cells. Note that Islet 4 has no insulitis, typical of the late-stage diabetic NOD mouse. Confocal high-power images of islets 2 and 3 are shown in Supplementary Figure 9. (b) Quantification of the frequency of islet cell types in control, prediabetic and late-stage NOD mice. (c) $\delta / \alpha$ ratio between control, prediabetic and late-stage NOD mice. Areas within the islet in which there is coexpression of multiple hormones, consistent with transdifferentiation, are shown in $\mathbf{d}-\mathbf{g}$ (insulin and glucagon colocalization) and $\mathbf{h}-\mathbf{k}$ (insulin and somatostatin colocalization). Scale bars for $\mathbf{d}-\mathbf{k}=20 \mu \mathrm{m}$. (I) Quantification of insulin and glucagon colocalization. (m) Quantification of insulin and somatostatin colocalization. Quantitative analysis of hormone colocalization was done using the ImageJ Mander's coefficient algorithm on confocal images of islets. Confocal images of islets 2 and 3 are shown in Supplementary Figure 9. (n) Quantification in each islet of the relationship between cells coexpressing insulin and glucagon or insulin and somatostatin. Islets with hormone coexpression were plotted by the extent of coexpression and further subdivided by islets with (red squares) and without (blue diamonds) insulitis. Error bars are S.E.M. ${ }^{\star} P<0.05$. ${ }^{\star \star \star} P<0.001$ 
$33 \%$ coexpressed somatostatin (Figure 6z). Islets were found where essentially all of the insulin-positive cells coexpressed somatostatin, with no glucagon-insulin coexpressing cells (Figures 6o-r and $v-x$, Supplementary Figure 14D and $E$ and $\mathrm{J}-\mathrm{M}$ ). This is most consistent with direct transdifferentiation from $\beta$ - to $\delta$-cells, but examination of additional patients will be required to determine how general this phenomenon is.

\section{Discussion}

Here, we demonstrate the existence of a novel pathway of islet cell neogenesis where $\alpha$-cells transdifferentiate first to $\beta$-cells, with a subset going on to transdifferentiate into $\delta$-cells. Transdifferentiation was induced by a single peptide, caerulein, which was sufficient in the context of severe $\beta$-cell deficiency to promote $\alpha$ - to $\beta$ - to $\delta$-cell transdifferentiation. A study of $\beta$-cell regeneration following profound $\beta$-cell ablation also found evidence of $\alpha$ - to $\beta$-cell transdifferentiation, but the efficiency of conversion was low. ${ }^{24}$ Ectopic expression of the transcription factor Pax4 under the control of the glucagon promoter led to conversion of duct cells into $\beta$-cells, further validating the ability of cells expressing glucagon to convert into $\beta$-cells. ${ }^{26,29}$ However, an important difference is that we have not observed evidence of induction of transdifferentiating cells in the ducts, either here or in our previous study using PDL plus alloxan. ${ }^{9}$

Although the genetic lineage tracing proved conclusively the existence of transdifferentiation from $\alpha$ - to $\beta$ - and $\alpha$ - to $\delta$-cells, the time course analysis verified that the transdifferentiation sequence was from $\alpha$ - to $\beta$ - to $\delta$-cells. The temporal appearance of $\delta$-cells and glucagon-insulin and insulin-somatostatin coexpressing intermediates, as well as the absence of glucagon-somatostatin coexpressing cells, is consistent with the transdifferentiation occurring from $\alpha$ - to $\beta$ - to $\delta$-cells, without direct $\alpha$ - to $\delta$-cell transdifferentiation (Figure 7).

Our data strongly indicate that hormone colocalization reflects transdifferentiation, as we never observed colocalization in normal mice. It was extremely rare even in the condition of pure $\beta$-cell ablation, studied previously by others. ${ }^{24} \mathrm{We}$ never observed glucagon-somatostatin coexpressing cells, which might have occurred if the hormone colocalization was an artifact of immunostaining. Similar to us, other groups have found hormone colocalization only in settings where transdifferentiation occurred as demonstrated by genetic lineage tracing. ${ }^{26,27}$ Consistent with our previous study of transdifferentiation following PDL plus alloxan, ${ }^{9}$ we never observed hormone colocalization in ducts, nor did we ever observe mG-positive cells in ducts.

$\beta$-cell dedifferentiation has been reported as occurring in response to deletion of FoxO1 and in type II diabetes. ${ }^{30,31}$ The finding of a high level of glucagon-insulin colocalization in the setting of profound $\beta$-cell ablation argues against $\beta$-cell dedifferentiation occurring following alloxan plus caerulein. First, there were simply not sufficient residual $\beta$-cells following alloxan to account for the large number of cells coexpressing glucagon and insulin. Also, dedifferentiation resulted in the loss of $\beta$-cell identity, that is, $\beta$-cell markers such as insulin, PDX1 and NKX6.1, before redifferentiation along a different lineage. ${ }^{30}$ The glucagon-insulin and insulin- somatostatin coexpression, as well as somatostatin and NKX6.1, is not consistent with that phenomenon ${ }^{30}$ and argues for transdifferentiation as opposed to dedifferentiation and redifferentiation as the mechanism responsible for $\alpha$ - to $\beta$ - to $\delta$-cell conversion.

The $\delta$-cell excess in murine ${ }^{32}$ and human T1D, with precisely the same intermediates as found in the alloxan plus caerulein model, demonstrates the relevance of endocrine cell transdifferentiation to autoimmune diabetes. However, endocrine cell transdifferentiation following alloxan plus caerulein occurred only in islets where there were few $\beta$-cells, whereas in T1D, transdifferentiation occurred in islets with a substantial number of residual $\beta$-cells, most likely reflecting a difference in the stimulus for transdifferentiation in autoimmunity versus that induced by caerulein. The simplest model that is consistent with the data presented here, postulating the existence of two factors, one positive and one repressive, is shown in Supplementary Figure 16.

In some human patients with T1D, islets were found with numerous $\beta$-cells, all of which coexpressed somatostatin, and with no evidence of $\alpha$ - to $\beta$-cell transdifferentiation, suggesting that direct $\beta$ - to $\delta$-cell transdifferentiation was taking place without an $\alpha$-cell origin. Such islets were fairly normal in morphology, with a large number of $\beta$-cells located more centrally, all of which coexpressed somatostatin but with no glucagon-insulin colocalization. Analysis of additional patient samples, which are rare, will be of value in determining the degree to which this occurs in the general population of type I diabetics. Of importance, islet cell transdifferentiation was found to occur regardless of age or duration of diabetes, suggesting that stimulating this process might be a viable approach to therapy in individuals with longstanding T1D. This is in contrast to $\beta$-cell replication, the other major approach to $\beta$-cell regeneration, which declines markedly with age, ${ }^{33-35}$ but is consistent with our previous finding in the PDL plus alloxan model, where $\alpha$ - to $\beta$-cell transdifferentiation occurred in old mice. ${ }^{9}$

The dramatic $\delta$-cell excess in murine and human T1D, combined with the observation that $\beta$-cells appear to be able to transdifferentiate directly into $\delta$-cells, indicates that the conventional paradigm of T1D where $\beta$-cells are destroyed by autoimmunity is incomplete. Rather, in addition to autoimmune destruction of $\beta$-cells, the view of islet cell kinetics in T1D should be modified to take into account the endocrine cell transdifferentiation from $\alpha$ - to $\beta$-cells and $\beta$ - to $\delta$-cells. If the process of $\beta$ to $\delta$-cell transdifferentiation is reversible, that may provide another route to $\beta$-cell regeneration in T1D. Regardless, the finding of efficient $\alpha$ - to $\beta$-cell transdifferentiation in T1D, as well as the finding that a single peptide is sufficient to drive transdifferentiation, raises the prospect that $\beta$-cell regeneration by the mobilization of $\alpha$ - and possibly $\delta$-cells functioning as facultative $\beta$-cell stem cells may be feasible.

\section{Materials and Methods}

Mice. Glu-mT/mG mice for $\alpha$-cell lineage tracing were a generous gift from $\mathrm{Dr}$. Mark Huising (The Salk Institute for Biological Studies, La Jolla, California (USA)).

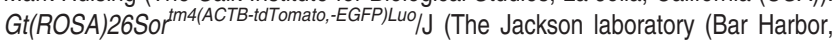
Maine)-stock \# 007576 ${ }^{36}$ were crossed with Glucagon-Cre mice, expressing cre recombinase under the control of the glucagon promoter. ${ }^{37}$ This transgene has been well characterized in multiple studies, exhibiting very low to undetectable 
background recombination. ${ }^{37,38} \mathrm{~F} 1$ mice were genotyped and mice positive for both markers were selected for the study. The F1 mice (Glu-mT/mG) have the mT cassette deleted in cre-expressing cells, while a membrane-targeted eGFP (mG) cassette is activated. Thus, $\alpha$-cells and cells derived from $\alpha$-cells that underwent cre-mediated recombination have a green fluorescent membrane, whereas preexisting cells not arising from recombined $\alpha$-cells have a red fluorescent membrane. To calculate the recombination efficiency in $\alpha$-cells, 444 cells from 12 mice were counted




C57BL/6 mice were purchased from Harlan Sprague Dawley, Inc. (Placentia, CA, USA). NOD mice were bred at the Sanford-Burnham Medical Research Institute, La Jolla, California. All animal experiments were approved by the Institutional Animal Care and Use Committee of the Sanford-Burnham Medical Research Institute in accordance with national regulations.

Alloxan plus caerulein. Mice were injected intravenously with $110 \mathrm{mg} / \mathrm{kg}$ alloxan (Sigma-Aldrich, St. Louis, MO, USA) in PBS (phosphate-buffered saline) at day 1. Mice with a blood glucose level greater than $500 \mathrm{mg} / \mathrm{dl}$ (OneTouch Ultra Mini, Johnson \& Johnson, Milpitas, CA, USA) were randomized into two groups. One group was injected with caerulein (Sigma-Aldrich; six IP injections on days 1, 3 and 5). Lineage tracing studies were done with a caerulein dose of $7 \mathrm{mg} / \mathrm{kg}$ and the time course study with C57BL/6 mice used a dose of $10 \mathrm{mg} / \mathrm{kg}$ in PBS. Mice (alloxan alone and alloxan plus caerulein) were killed on days:

Day 13- Three C57BL/6 alloxan plus caerulein mice, three C57BL/6 alloxan alone mice.
Day 20- Three lineage tracing alloxan plus caerulein mice, three lineage tracing alloxan alone mice, seven C57BL/6 alloxan plus caerulein mice, seven C57BL/6 alloxan alone mice. Of the seven C57BL/6 alloxan plus caerulein mice and seven alloxan alone mice, one group from each $(n=3)$ had BrdU (1 mg/ml, Sigma-Aldrich) added to the drinking water, whereas the second $(n=4)$ had no BrdU added.

Day 27- Three C57BL/6 alloxan plus caerulein mice, three C57BL/6 alloxan alone mice.

Day 38- Three lineage tracing alloxan plus caerulein mice, three lineage tracing alloxan alone mice, four C57BL/6 alloxan plus caerulein and four C57BL/6 alloxan alone.

NOD mouse experiments. Twenty 8.5 month-old non-diabetic NOD mice (blood glucose levels $80-200 \mathrm{mg} / \mathrm{dl}$ ) and five diabetic NOD mice (age 6-15 months-old) were killed. Of the 20 non-diabetic NOD mice, six had an islet morphology typical of early stages of diabetes-that is, some islets with insulitis, disorganized islet morphology and transdifferentiating cells. Fourteen non-diabetic mice had no evidence of islet autoimmunity and were not analyzed further.

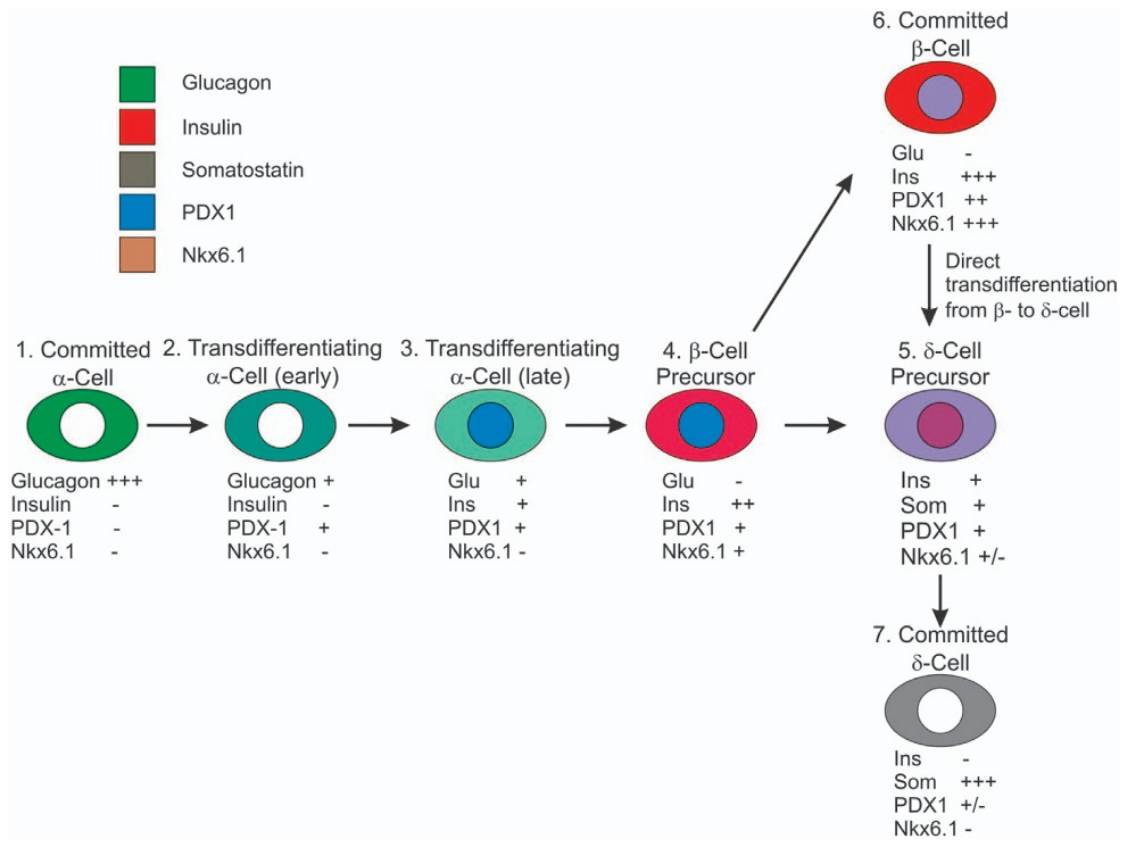

Figure 7 Model of pancreatic islet cell transdifferentiation. Intermediates in the transdifferentiation process are documented as follows: intermediate 2 is shown in Supplementary Figures $4 \mathrm{C}$ and D (surrounded by a white line), intermediate 3 in Supplementary Figure 4C (surrounded by a yellow line) and intermediate 5 in Supplementary Figure 5 and Figures $3 c$ and $d$

Figure 6 Pancreatic $\delta$-cells increase over time in patients with T1D. (a) pancreas from non-diabetic donor (nPOD 6140), demonstrating normal islet morphology and hormone expression. (b) pancreas from nPOD Donor \#6052 (T1D for 1 year), demonstrating the $\alpha$-cell predominance found in most of the pancreas of this patient. (c) Pancreas from nPOD Donor \#6159 (T1D for 44 years), demonstrating $\delta$-cell predominance. (d) Pancreas from a patient with type II diabetes (T2D) for 20 years, demonstrating mild loss of $\beta$-cells and no increase in $\delta$-cells. For a-d, scale bar $=280 \mu \mathrm{m}$ for low-power images and $=75 \mu \mathrm{m}$ for high-power images. (e) Quantification of the somatostatin-positive area normalized to the glucagon-positive area, demonstrating an increase over time with T1D. Red diamonds mark the age of type I diabetics and red squares mark the duration of T1D, connected by a black line for each patient. Blue circles mark the age of non-diabetic patients. Pearson's coefficient for T1D was 0.61 and for non-diabetic patients was -0.74 . (f) Quantification of the somatostatin-positive area normalized to the glucagon-positive area in patients with T1D greater than 20 years, compared with non-diabetic and type II diabetic patients, demonstrating a statistically significant increase in the number of $\delta$-cells in the type I diabetic patients with years of disease. (g-r) Islet hormone coexpression in a non-diabetic patient (NPOD Donor \#6178) ( $\mathbf{g}-\mathbf{j})$, nPOD Donors \#6052 and \#6038, with T1D for 1 year (k-n) and 20 years (o-r), respectively. Coexpression was analyzed by the ImageJ colocalization analysis highlighter algorithm that analyzes two channels (red and green) and marks colocalized areas in white. Insulin and glucagon (red and green in $\mathbf{g}, \mathbf{k}$ and $\mathbf{~}$ ), insulin and somatostatin (red and green in $\mathbf{h}, \mathbf{I}$ and $\mathbf{p}$ ), and somatostatin and glucagon (red and green in $\mathbf{i}, \mathbf{m}$ and $\mathbf{q}$ ). Note that all of the colors from the Image $\mathbf{J}$ analysis are pseudocolors. True colors from the same islets are shown in $\mathbf{j}, \mathbf{n}$ and $\mathbf{r}$. Examples of insulin and glucagon coexpression are shown in high power in $\mathbf{s}$ and $\mathbf{t}$ (double positive areas are indicated by a dashed white line), and of insulin and somatostatin coexpression in $\mathbf{u}-\mathbf{x}$ (double positive areas are indicated by a dashed yellow line). Quantification of insulin and glucagon coexpression is presented in y and for insulin and somatostatin in $\mathbf{z}$ in nPOD Donors \#6052, \#6196, \#6081 and \#6038 (Supplementary Table 1). These patients were selected because their pancreas had islets with a significant number of $\beta$-cells and only islets with greater than $20 \beta$-cells were subjected to quantitative analysis. No colocalization between glucagon and somatostatin was found and so it could not be quantified. Coexpression was indistinguishable from background in the normal patient, but there was extensive insulin-glucagon coexpression in nPOD patients 6052, 6196 and 6081 . Donors 6081 and $6038 \mathrm{had}$ a high level of insulin and somatostatin coexpression. Quantification was performed on confocal images (Supplementary Figure 14). Error bars are S.E.M. of individual islets. Islets from five non-diabetic patients were pooled. Scale bar for $\mathbf{i}-\mathbf{t}=75 \mu \mathrm{m}$ 
Human pancreatic tissue. Human pancreatic tissue was obtained from the Network for Pancreatic Organ Donors with Diabetes (nPOD), a collaborative T1D research project sponsored by JDRF. Organ Procurement Organizations (OPO) partnering with nPOD to provide research resources are listed at http:// www.jdrfnpod.org/our-partners.php. Use of that tissue was approved by the SBMRI IRB (IRB-2013-019-13). All images from nPOD samples are available from the nPOD at http://www.jdrfnpod.org/online-pathology.php. A summary of the human patients is in Supplementary Table 1.

Immunohistochemical staining. Tissue was fixed in $4 \%$ formaldehyde over night at $4{ }^{\circ} \mathrm{C}$ (USB; OH, USA), washed in PBS, followed by overnight in $30 \%$ sucrose at $4^{\circ} \mathrm{C}$, then embedded in OCT (Optimal Cutting Temperature) (Sakura Finetek; CA, USA) and frozen at $80^{\circ} \mathrm{C}$. Slides of $5-\mu \mathrm{m}$ thickness were washed four times with PBS and treated with $0.3 \%$ Triton in PBS for $10 \mathrm{~min}$. Antigen retrieval (when applicable) was done using with CitriSolvTM (Fisher Scientific, PA, USA) for 7 or $10 \mathrm{~min}$ in sub-boiling temperature. After washing with PBS for 10 min, slides were incubated in blocking solution with $5 \%$ normal donkey serum (Jackson Immuno Research, PA, USA) for $60 \mathrm{~min}$ at room temperature. Human slides were fixed in $4 \%$ formaldehyde for $20 \mathrm{~min}$ at $4{ }^{\circ} \mathrm{C}$, whereas all cryosections of $5-\mu \mathrm{m}$ thickness were incubated with antisera specific for insulin (1/200, guinea pig, USBIO, Swampscott, MA, USA), insulin (1/200, rabbit, Santa Cruz Biotechnology, Santa Cruz, CA, USA), glucagon (1/2000, mouse, Sigma-Aldrich), somatostatin (1/200, goat, Santa Cruz Biotechnology), PDX1 (1/2000, goat, Abcam, Cambridge, MA, USA), NKX6.1 (1/1000, mouse, Beta Cell Biology Consortium, Nashville, TN, USA), 5-bromodeoxyuridine (BrdU; mouse, GE healthcare, Piscataway, NJ, USA). Secondary antibodies for detection of guinea pig, rabbit, goat or mouse antibodies were labeled with: Alexa Fluor 488 (Invitrogen, Carlsbad, CA, USA), Alexa Fluor 649 (Jackson ImmunoResearch Laboratories, West Grove, PA, USA), Rhodamine Red (Jackson ImmunoResearch Laboratories), Cy5 (Jackson ImmunoResearch Laboratories) and Dylight 405 (Jackson ImmunoResearch Laboratories). Nuclei were visualized with DAPI (4',6diamidino-2- phenylindole; Sigma-Aldrich).

Imaging and image analysis. All slides were scanned at a magnification of $\times 20$ using the Aperio Scanscope FL system (Aperio Technologies Inc., Vista, CA, USA). The appropriate dyes were assigned and illumination levels were calibrated using a preset procedure, the parameters were saved and applied to all slides. The acquired digital images represent whole tissue sections. Each section was $6-\mu \mathrm{m}$ thick and calculations per islet reflect a section through that islet. Sections were evaluated for image quality. All acquired images were subsequently placed in dedicated project folders, and stored on a designated local server. Slides were viewed and analyzed using the web-based Image Scope viewer. Slides were quantified using the 'Area Quantification FL' algorithm (version 11 Aperio Technologies Inc.). The algorithm was optimized using a preset procedure and the subsequent macro was saved and applied to all slides.

Confocal images of the lineage experiment were acquired using Zeiss LSM710 or 780 confocal microscopes (Zeiss, Jena, Germany) at the Waitt Advanced Biophotonics Center Core Facility of the Salk Institute for Biological Sciences. Other confocal images were acquired using Olympus Fluoview FV1000 (Olympus Optical, Tokyo, Japan) at the SBMRI Imaging Core Facility.

Images of islet cells from the lineage tracing experiment were scored as expressing eGFP or mT on their plasma membranes. Only cells that had continuous, unbroken staining for the membrane markers were included in the analysis of hormone expression. Quantification and determination of double- and triple-positive cells was done using the Aperio Scanscope FL system as described above. Four slides that were $100 \mu \mathrm{M}$ apart were analyzed from each C57BL/6 or NOD mouse. Confocal images were analyzed with ImageJ (NIH, Bethesda, MD, USA) for visualized colocalization (colocalization highlighter algorithm) and quantified (Mander's coefficient algorithm). Human samples were scanned (Aperio Scanscope FL system) and analyzed as described above. A complete set of the confocal images used for this analysis is in Supplementary Movie 1.

Statistics. Because an a priori hypothesis was being tested, $P$-values were calculated as one-tailed homoscedastic Student's t-tests except in Figure $4 \mathrm{~g}$, where a two-sample proportion test was used.

\section{Conflict of Interest}

The authors declare no conflict of interest.
Acknowledgements. This work was supported by the Sanford Children's Health Research Center, BetaBat (in the Framework Program 7 of the European Community) and CIRM grant TG2-01162. We are grateful for assistance from SBMRI Core personnel Guillermina Garcia and Robbin Newlin (Histopathology), Leslie Boyd and Ed Monosov (Cell Imaging), Xiayu (Stacy) Huang (statistics; bioinformatics). We acknowledge Dr. Mark Huising of the Salk Institute for providing the gcg-cre $\times \mathrm{mTmG}$ mice used for the lineage tracing study and for acquiring confocal images of these mice. We thank Ze'ev Ronai for a helpful discussion and $\mathrm{nPOD}$ for providing slides of human pancreatic tissue.

1. Eguizabal C, Montserrat N, Veiga A, Izpisua Belmonte JC. Dedifferentiation, transdifferentiation, and reprogramming: future directions in regenerative medicine. Semin Reprod Med 2013; 31: 82-94.

2. Atkinson MA, Eisenbarth GS, Michels AW. Type 1 diabetes. Lancet 2013; S0140-6736: 60594-60597.

3. Levine F, Itkin-Ansari P. beta-cell Regeneration: neogenesis, replication or both? J Mol Med (Berl) 2008; 86: 247-258.

4. Inada A, Nienaber C, Katsuta H, Fujitani Y, Levine J, Morita R et al. Carbonic anhydrase IIpositive pancreatic cells are progenitors for both endocrine and exocrine pancreas after birth. Proc Natl Acad Sci USA 2008; 105: 19915-19919.

5. Bonner-Weir S, Inada A, Yatoh S, Li WC, Aye T, Toschi E et al. Transdifferentiation of pancreatic ductal cells to endocrine beta-cells. Biochem Soc Trans. 2008; 36(Pt 3): 353-356.

6. Hao E, Tyrberg B, Itkin-Ansari P, Lakey JR, Geron I, Monosov EZ et al. Beta-cell differentiation from nonendocrine epithelial cells of the adult human pancreas. Nat Med 2006; 12: 310-316.

7. Xu X, D’Hoker J, Stange G, Bonne S, De Leu N, Xiao X et al. Beta cells can be generated from endogenous progenitors in injured adult mouse pancreas. Cell 2008; 132: 197-207.

8. Lee $\mathrm{SH}$, Hao E, Levine $\mathrm{F}$. beta-Cell replication and islet neogenesis following partial pancreatectomy. Islets 2011; 3: 188-195.

9. Chung $\mathrm{CH}, \mathrm{Hao} \mathrm{E}$, Piran R, Keinan E, Levine F. Pancreatic beta-cell neogenesis by direct conversion from mature alpha-cells. Stem Cells. 2010; 28: 1630-1638.

10. Rankin MM, Wilbur CJ, Rak K, Shields EJ, Granger A, Kushner JA et al. Beta cells are not generated in pancreatic duct ligation induced injury in adult mice. Diabetes 2013; 62: 1634-1645.

11. Xiao X, Chen Z, Shiota C, Prasadan K, Guo P, El-Gohary Y et al. No evidence for beta cell neogenesis in murine adult pancreas. J Clin Invest 2013; 123: 2207-2217.

12. Baeyens L, Lemper M, Leuckx G, De Groef S, Bonfanti P, Stange G et al. Transient cytokine treatment induces acinar cell reprogramming and regenerates functional beta cell mass in diabetic mice. Nat Biotechnol 2013; 32: 76-83.

13. Nagasao J, Yoshioka K, Amasaki H, Mutoh K. Centroacinar and intercalated duct cells as potential precursors of pancreatic endocrine cells in rats treated with streptozotocin. Ann Anat 2003; 185: 211-216.

14. Chung $\mathrm{CH}, \mathrm{Hao} E \mathrm{EG}$, Piran R, Keinan E, Levine F. Pancreatic beta-cell neogenesis by direct conversion from mature alpha-cells. Stem Cells 2010; 28: 1630-1638.

15. Chung $\mathrm{CH}$, Levine $\mathrm{F}$. Adult pancreatic alpha-cells: a new source of cells for beta-cell regeneration. Rev Diabet Stud 2010; 7: 124-131.

16. Hao E, Lee SH, Levine F. Efficient beta-Cell regeneration by a combination of neogenesis and replication following beta-cell ablation and reversal of pancreatic duct ligation. Stem Cells 2013; 31: 2388-2395.

17. Lerch MM, Gorelick FS. Models of acute and chronic pancreatitis. Gastroenterology 2013; 144: 1180-1193.

18. Zaninovic V, Gukovskaya AS, Gukovsky I, Mouria M, Pandol SJ. Cerulein upregulates ICAM-1 in pancreatic acinar cells, which mediates neutrophil adhesion to these cells. Am J Physiol Gastrointest Liver Physiol 2000; 279: G666-G676.

19. Jensen JN, Cameron E, Garay MV, Starkey TW, Gianani R, Jensen J. Recapitulation of elements of embryonic development in adult mouse pancreatic regeneration. Gastroenterology 2005; 128: 728-741.

20. Jensen J, Serup P, Karlsen C, Nielsen TF, Madsen OD. mRNA profiling of rat islet tumors reveals nkx 6.1 as a beta-cell- specific homeodomain transcription factor. J Biol Chem 1996; 271: 18749-18758.

21. Sander M, Sussel L, Conners J, Scheel D, Kalamaras J, Dela Cruz F et al. Homeobox gene Nkx6.1 lies downstream of Nkx2.2 in the major pathway of beta-cell formation in the pancreas. Development 2000; 127: 5533-5540.

22. Peshavaria M, Gamer L, Henderson E, Teitelman G, Wright CV, Stein R. XIHbox 8, an endoderm-specific Xenopus homeodomain protein, is closely related to a mammalian insulin gene transcription factor. Mol Endocrinol 1994; 8: 806-816.

23. Neumuller RA, Knoblich JA. Dividing cellular asymmetry: asymmetric cell division and its implications for stem cells and cancer. Genes Dev 2009; 23: 2675-2699.

24. Thorel F, Nepote V, Avril I, Kohno K, Desgraz R, Chera S et al. Conversion of adult pancreatic alpha-cells to beta-cells after extreme beta-cell loss. Nature 2010; 464: 1149-1154.

25. Nir T, Melton DA, Dor Y. Recovery from diabetes in mice by beta cell regeneration. J Clin Invest 2007; 117: 2553-2561. 
26. Al-Hasani K, Pfeifer A, Courtney M, Ben-Othman N, Gjernes E, Vieira A et al. Adult duct-lining cells can reprogram into beta-like cells able to counter repeated cycles of toxin-induced diabetes. Dev Cell 2013; 26: 86-100.

27. Wilcox CL, Terry NA, Walp ER, Lee RA, May CL. Pancreatic alpha-cell specific deletion of mouse Arx leads to alpha-cell identity loss. PLoS One 2013; 8: e66214.

28. Lee SH, Demeterco C, Geron I, Abrahamsson A, Levine F, Itkin-Ansari P. Islet specific Wnt activation in human type II diabetes. Exp Diabetes Res 2008; 2008 728763.

29. Collombat P, Xu X, Ravassard P, Sosa-Pineda B, Dussaud S, Billestrup N et al. The ectopic expression of Pax4 in the mouse pancreas converts progenitor cells into alpha and subsequently beta cells. Cell 2009; 138: 449-462.

30. Talchai C, Xuan S, Lin HV, Sussel L, Accili D. Pancreatic beta cell dedifferentiation as a mechanism of diabetic beta cell failure. Cell 2012; 150: 1223-1234.

31. Fiori JL, Shin YK, Kim W, Krzysik-Walker SM, Gonzalez-Mariscal I, Carlson OD et al. Resveratrol prevents beta-cell dedifferentiation in nonhuman primates given a high-fat/ high-sugar diet. Diabetes 2013; 62: 3500-3513.

32. Reddy S, Chai RC, Rodrigues JA, Hsu TH, Robinson E. Presence of residual beta cells and co-existing islet autoimmunity in the NOD mouse during longstanding diabetes: a combined histochemical and immunohistochemical study. J Mol Histol 2008; 39: 25-36.

33. Teta M, Long SY, Wartschow LM, Rankin MM, Kushner JA. Very slow turnover of betacells in aged adult mice. Diabetes 2005; 54: 2557-2567.

34. Perl S, Kushner JA, Buchholz BA, Meeker AK, Stein GM, Hsieh M et al. Significant human beta-cell turnover is limited to the first three decades of life as determined by in vivo thymidine analog incorporation and radiocarbon dating. J Clin Endocrinol Metab 2010; 95 E234-E239.
35. Lee SH, Itkin-Ansari P, Levine F. CENP-A, a protein required for chromosome segregation in mitosis, declines with age in islet but not exocrine cells. Aging (Albany NY) 2010; 2: 785-790.

36. Muzumdar MD, Tasic B, Miyamichi K, Li L, Luo L. A global double-fluorescent Cre reporter mouse. Genesis 2007; 45: 593-605.

37. Herrera PL. Adult insulin- and glucagon-producing cells differentiate from two independent cell lineages. Development 2000; 127: 2317-2322.

38. Quoix N, Cheng-Xue R, Guiot Y, Herrera PL, Henquin JC, Gilon P. The GluCreROSA26EYFP mouse: a new model for easy identification of living pancreatic alpha-cells. FEBS Lett 2007; 581: 4235-4240.

39. Guo S, Dai C, Guo M, Taylor B, Harmon JS, Sander M et al. Inactivatixon of specific beta cell transcription factors in type 2 diabetes. J Clin Invest 2013; 123: 3305-3316.Supplementary Movie 1

Cell Death and Disease is an open-access journal published by Nature Publishing Group. This work is licensed under a Creative Commons Attribution-NonCommercialShareAlike 3.0 Unported License. The images or other third party material in this article are included in the article's Creative Commons license, unless indicated otherwise in the credit line; if the material is not included under the Creative Commons license, users will need to obtain permission from the license holder to reproduce the material. To view a copy of this license, visit http://creativecommons.org/ licenses/by-nc-sa/3.0/

Supplementary Information accompanies this paper on Cell Death and Disease website (http://www.nature.com/cddis) 